\title{
OPTICAL PROPERTIES AND CHEMICAL CHARACTERIZATION OF WOODY SYRUP BY USING METHODS OF APPLIED PHOTONICS
}

\author{
Poli Radusheva ${ }^{1}$, Krastena Nikolova ${ }^{1}$, Nadezhda Petkova ${ }^{2}$, Radoslava Gabrova ${ }^{3}$, \\ Darina Naydenova ${ }^{4}$ \\ 1) Department of Physics and Biophysics, Faculty of Pharmacy, Medical University \\ - Varna, Bulgaria \\ 2) Department of Organic Chemistry and Inorganic Chemistry, Technological \\ Faculty, University of Food Technologies- Plovdiv, Bulgaria \\ 3) Department of Computer systems and Technologies, Technical Faculty, \\ University of Food Technologies- Plovdiv, Bulgaria \\ 4) Department of Preclinical and Clinical sciences, Faculty of Pharmacy, Medical \\ University - Varna, Bulgaria.
}

\begin{abstract}
:
Introduction: The natural woody syrup is a typical product from the Canary Islands and America. It is often used for health food supplement for children, athletes and elderly because it has well-pronounced antioxidant properties. The interest in this syrup is increasing because it is often used in homeopathic medicine and consists of phenolic content. Antioxidants reduce cell damaging effects of free radicals. They are more effective in vitro antioxidants than vitamins $\mathrm{D}$ and $\mathrm{C}$ and have a significant effect towards protection of unwanted in vivo oxidation of proteins and lipids.
\end{abstract}

Objective: The natural woody syrup is prepared from Canadian maple syrup and syrup from 5 types of palms from Southeast Asia. The nutritional properties (such as the content of sugars) were analyzed. The antioxidant activity, total phenolic content and optical properties have been investigated.

Purpose: The aim of this study is to explore the relations between fluorescence in natural woody syrup and its total phenolic content and total antioxidant activity in view of the usefulness of this product for human health and to determine their nutrient composition by the physicochemical properties.

Materials and methods: The natural woody syrup will be investigated by using methods of applied photonic, 2,2-Diphenyl-1-picrylhydrazyl (DPPH) and Ferric reducing antioxidant power (FRAP) methods for antioxidant activity, Folin-Ciocalteu reagent for total phenols and HighPerformance Liquid Chromatography Refractive Index Detector HPLC-RID analysis for determination of the sugar content.

Results: The dependence between antioxidant activity and total phenolic content was established. The sample has a small quantity of flavonoids, and for this reason, there is not the distinct peak at $380 \mathrm{~nm}$. Excitation in the visible region is suitable for distinguishing the riboflavin and pigments.

Conclusions: The fluorescence of the syrup was correlated with their antioxidant activity. Two emission fluorescence maxima have been observed:

- The first one is attributed to the riboflavin in the region $550 \mathrm{~nm}-580 \mathrm{~nm}$

- The second one is connected with the pigments similar to the chlorophyll at about $690 \mathrm{~nm}$

Keywords: natural woody syrup, fluorescence spectroscopy, phenolic content, antioxidant activity, sugar content

\section{INTRODUCTION:}

The natural woody syrup is a typical product from the Canary Islands and America [1]. It is made from maple sap and palms syrup, which contain some minerals as $\mathrm{Mn}$, $\mathrm{Fe}, \mathrm{K}, \mathrm{Na}, \mathrm{Ca}$ and $\mathrm{Zn}$ [2]. The purpose of this investigation is to determinate the nutrition composition of the syrup and relation between antioxidant activity and some substances with phenolic character by using the parameters of applied photonics. These properties of the syrup are important because the latter is used with great success in the cases:

- Edema degradation (haematomas)

- Improved limited mobility of the joints

- Reducing chronic pain.

\section{MATERIALS AND METHODS:}

\section{Samples:}

Natural woody syrup from Switzerland has been investigated. It consists of Canadian maple syrup and syrup from 5 types of palms from Southeast Asia. The syrup is obtained from trees growing in natural conditions.

The natural Canadian maple syrup is obtained from 40 years old trees and must be concentrated to be protected from fermentation. It is from "class C" and has high mineral content. The palm syrup comprises coconut palms, palms 
from the rain forests, palms of swamps places and palms trees from Sri Lanka.

Methods:

Total phenolic content (TPC) was measured using a Folin-Ciocalteu reagent [3] with some modifications. Briefly, Folin-Ciocalteu reagent $(1 \mathrm{~mL})$ diluted five times was mixed with $0.2 \mathrm{ml}$ sample and $0.8 \mathrm{ml} 7.5 \% \mathrm{Na}_{2} \mathrm{CO}_{3}$. The reaction was performed for $20 \mathrm{~min}$ at room temperature in darkness. Then the absorbance was measured at $765 \mathrm{~nm}$ against a blank, prepared with $70 \%$ methanol. The results were expressed as mg equivalent of gallic acid (GAE) according to the calibration curve, linear in the range of $0.02-0.10 \mathrm{mg}$ gallic acid used as a standard [3].

The total flavonoids content was analyzed by $\mathrm{Al}\left(\mathrm{NO}_{3}\right)_{3}$ reagents. The absorbance was measured at $415 \mathrm{~nm}$ against blank. The results were presented as mg equivalents quercetin (QE) per g dry weight (dw) [4].

The antioxidant activities were evaluated by two methods: DPPH (1,1-diphenyl-2-picrylhydrazyl) radical based on mixed hydrogen atom transfer (HAT) and single electron transfer mechanisms and FRAP (ferric reducing antioxidant power) based only on single electron transfer mechanism.

\section{The DPPH radical-scavenging ability}

The analyzed sample $(0.15 \mathrm{ml})$ was mixed with 2.85 $\mathrm{ml}$ freshly prepared $0.1 \mathrm{mM}$ solution of DPPH in methanol. The sample was incubated for $15 \mathrm{~min}$ at $37^{\circ} \mathrm{C}$ in darkness. The reduction of absorbance at $517 \mathrm{~nm}$ was measured by spectrophotometer in comparison to the blank containing methanol and \% inhibition was calculated [4]. A standard curve was built with 6-hydroxy-2,5,7,8-tetramethylchroman- 2- carboxylic acid (Trolox) in concentration between 0.005 and $1.0 \mathrm{mM}$. The results were expressed in $\mathrm{mM}$ Trolox ${ }^{\circledR}$ equivalents (TE).

Ferric reducing antioxidant power (FRAP) assay

The assay was performed according to [5] with slight modification. The FRAP reagent was freshly by mixing 10 parts $0.3 \mathrm{M}$ acetate buffer $(\mathrm{pH} 3.6), 1$ part 10
$\mathrm{mM}$ 2,4,6- tripyridyl-s-triazine (TPTZ) in $40 \mathrm{mM} \mathrm{HCl}$ and 1 part $20 \mathrm{mM} \mathrm{FeCl} 3.6 \mathrm{H}_{2} \mathrm{O}$ in d. $\mathrm{H} 2 \mathrm{O}$. The reaction was started by mixing $3.0 \mathrm{ml}$ FRAP reagent with $0.1 \mathrm{ml}$ of investigated extract. The reaction time was $10 \mathrm{~min}$ at 37 ${ }^{\circ} \mathrm{C}$ in darkness, and the absorbance was measured at 593 $\mathrm{nm}$ against blank prepared with methanol. Antioxidant activity was expressed as mM Trolox ${ }^{\circledR}$ equivalents (TE).

\section{Determination of total soluble carbohydrates}

The total soluble carbohydrate content was estimated by the phenol-sulphuric acid method. The reducing sugars were estimated by PAHBAH method at 410 $\mathrm{nm}$. Chromatographic separations and determination of presented sugars were performed on an HPLC instrument Elite Chrome Hitachi, coupled with refractive index detector (RID) Chromaster 5450. The separation was done on a Shodex ${ }^{\circledR}$ Sugar SP0810 (300 mm $\times 8.0 \mathrm{~mm}$ i.d.) with $\mathrm{Pb}^{2+}$ and a guard column Shodex SP - G $(5 \mu \mathrm{m}, 6 \times 50$ $\mathrm{mm}$ ) operating at $85^{\circ} \mathrm{C}$, mobile phase $\mathrm{d} . \mathrm{H}_{2} \mathrm{O}$ with flow rate of $1.0 \mathrm{ml} / \mathrm{min}$ and the injection volume of properly diluted sample $20 \mu \mathrm{l}$ [6].

\section{Fluorescence measurement}

The sources used to measure the fluorescence spectra are $295 \mathrm{~nm}, 395 \mathrm{~nm}, 405 \mathrm{~nm}, 410 \mathrm{~nm}, 415 \mathrm{~nm}$ light emitting diodes (LEDs). A fiber optic spectrometer (Brolight, Avantes) with sensitivity in the (200-1100) nm range and a resolution of about $8 \mathrm{~nm}$ was used to measure the fluorescence spectra. The syrup was placed in a cuvette $1 \mathrm{~mm} \times 1 \mathrm{~mm}$ and irradiated by laser diodes (LDs) or light emitting diodes (LEDs).

\section{Statistical procedures}

All results are obtained in triplicate. The standard deviation was given in the table. The excitation -emission matrix was obtained by using MATLAB 9.0.

\section{RESULTS:}

The content of total soluble carbohydrate in natural woody syrup was summarized in Table 1 .

Table 1. Soluble carbohydrate content in woody syrup, g/100 g

\begin{tabular}{|c|c|c|c|c|}
\hline $\begin{array}{c}\text { Total soluble } \\
\text { carbohydrates }\end{array}$ & Reducing sugars & Sucrose & Glucose & Fructose \\
\hline $58,98 \pm 2,12$ & $20,07 \pm 0.2$ & $38,57 \pm 0,12$ & $11,43 \pm 2,09$ & $6,22 \pm 0,96$ \\
\hline
\end{tabular}

The dependence between the parameters of applied photonics and total phenolic content exists. The content of biologically active substances and antioxidant activity was presented in Table 2. FRAP assay gave higher results than DPPH assay. This showed that antioxidant activity was due mainly to a phenolic substance that activates a single electron transfer mechanism.

Table 2. Total phenols, flavonoids and antioxidant activity of woody syrup

\begin{tabular}{|c|c|c|c|}
\hline $\begin{array}{c}\text { Total phenolic content, } \\
\text { mg GAE/g }\end{array}$ & $\begin{array}{c}\text { Total flavonoids, } \\
\mathrm{mg} \mathrm{QE} / \mathrm{g}\end{array}$ & DPPH & FRAP \\
\cline { 3 - 4 } & $0,27 \pm 0,08$ & $19,61 \pm 0,24$ & $24,99 \pm 0,85$ \\
\hline
\end{tabular}


The fluorescence spectra are determined with illumination the sample with light with wavelength into UV and visible region.
The obtained spectra in the UV region were not presented, because of the appearance of some noises. But they are used for determination of the finger print for the natural woody syrup. On the Fig. 2 the excitation emission matrix has been drawn, and two dimensional counter map was also presented.

Fig. 1. Fluorescence spectra in the visible region for natural woody syrup

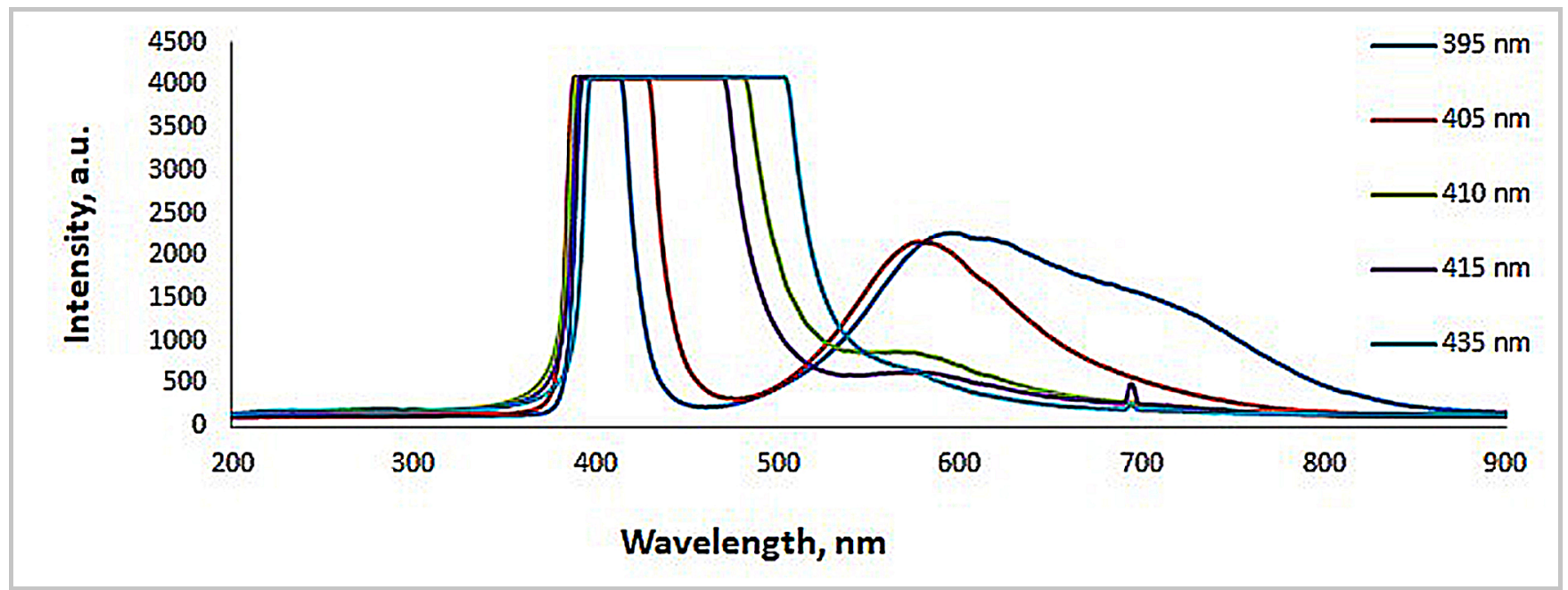

Fig. 2. Excitation emission matrix and counter map for a natural woody syrup

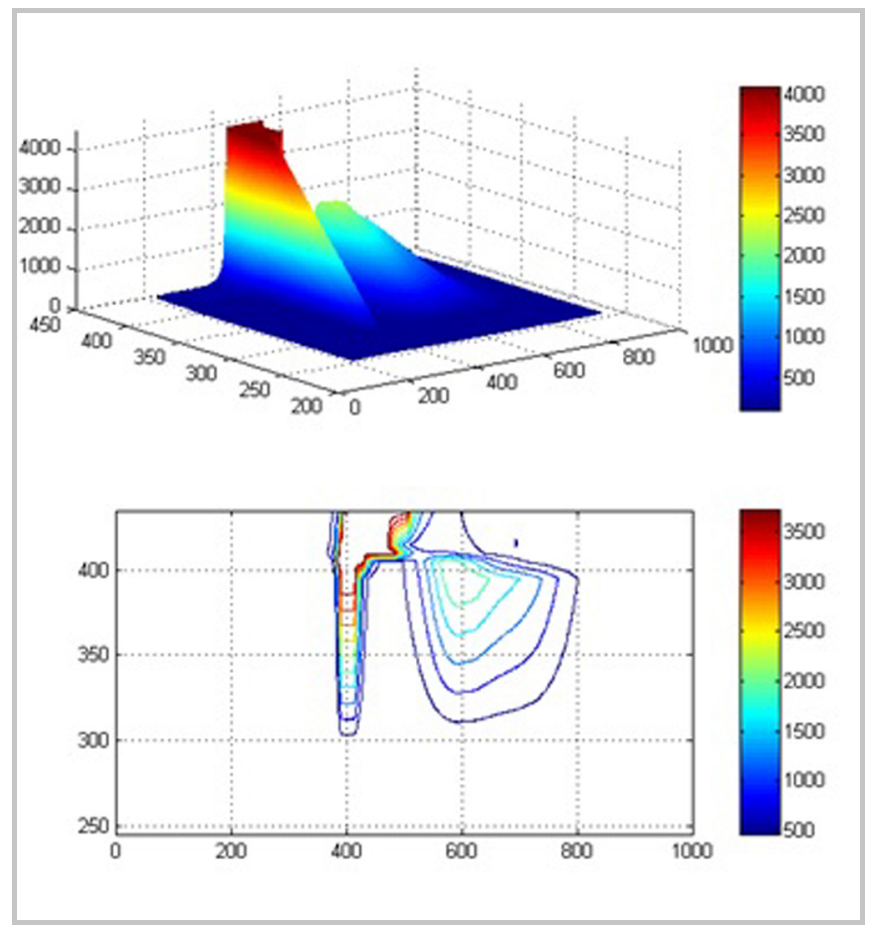

DISCUSSION:

According to the measurement of fluorescence in the $\mathrm{UV}$ region, there is one weak peak at $280 \mathrm{~nm}$. One possibility for the source of fluorescence signal was some phenolic compounds. The similar conclusion is made for southwestern Maple syrup from Kermashla and Dumont [7]. There are two fluorescence maxima in the visible region:
- The first emission peak of syrup is observed between $550 \mathrm{~nm}-580 \mathrm{~nm}$ when the sample is exited with light at the range of 340 to $410 \mathrm{~nm}$. This peak can be related with the presence of riboflavin. The similar peak is reported from Sikorovska and co-authors [8].

- The second fluorescence maximum is around to $690 \mathrm{~nm}$, and it is connected with pigments similar to the chlorophyll. It is observed only for excitation wavelength $415 \mathrm{~nm}$.

From the spectra obtained by using methods of applied photonic can be concluded that the natural woody syrup contains the riboflavin, a small quantity of chlorophyll pigments and phenolic compounds.

It is expressed in Trolox equivalent. The values determined by the used methods are similar. A connection between total phenol content and AOA exists. As known, the phenolic compounds effectively capture free radicals [9-11]. The low content of total flavonoids was found. For this reason, an emission peak in fluorescence spectra in UV region is not observed at $380 \mathrm{~nm}$.

The significant content of polyphenols is determined in the investigated syrup. They are organic compounds from different chemical nature including phenolic acids, flavonoids, glucosides. In combination with vitamins and carotenoids, they protect tissues of the body from oxidative stress.

In general, investigated natural woody syrup contained a significant amount of soluble carbohydrates $(58.98 \mathrm{~g} / 100 \mathrm{~g})$. The sample is rich in mono- and disaccharides. HPLC-RID analysis revealed in details the presence only of sucrose, glucose and fructose as individual sugars in this sample. Moreover, the values of sucrose $(38,57 \mathrm{~g} / 100 \mathrm{~g})$ significantly dominated above 
monosaccharide. The similar tendency was observed with carob flour and syrup repapered form it husks and pods [6]. The content of investigated sugars is similar to this of the palm tree syrup reported [12]. This fact can be explained by climate and harvest conditions. There was a slight tendency for decreasing of sucrose and increasing the concentration of glucose and fructose. It depends on the climate, humidity and acidity of syrup. Fructose was in lower values in comparison of other sugars. Therefore, the natural woody syrup was evaluated as a natural source of energy, due to high sucrose content in it.

\section{CONCLUSION}

The natural woody syrup is a supersaturated solution of sugars and water, it is rich of phenolic components. It can be suggested as a natural product, which could be suitable raw materials of production of natural sweeteners. The biologically active substances and related with them antioxidant activity contribute to the interaction with many basic cellular activities, acts with the free radicals and exhibit cardio-health protection.

The optical properties as absorbance and fluorescence can be used for the qualitative determination of pigments and some vitamins. The phenolic compounds are the influential factors of the color and flavour of the syrup. Therefore, this complex of phytochemical active substances in natural woody syrup offers various fields of prospective applications in medicine and nutrition for healthy food production.

\section{REFERENCES:}

1. Ball DW. The Chemical Composition of Maple Syrup. J Chem Educ. 2007; 84(10):1647. [Crossref]

2. Tanako H. Investigation of chemical and Physical properties of Southwestern Wisconsin maple syrup. Journal of student research. 2006;97107.

3. Stintzing FC, Nerbach KM, Mosshammer MR, Carle R, Yi W, Sellappan S, et al. Color, betalain pattern, and antioxidant properties of cactus pear (Opuntia spp.) clones. J. Agric Food Chem. 2005 Jan 26; 53(2): 442-451. [PubMed] [CrossRef]

4. Ivanov IG, Vrancheva RZ, Marchev AS, Petkova NT, Aneva YI, Denev PP, et al. Antioxidant activities and phenolic compounds in Bulgarian Fumaria species. Int J Curr Microbiol App Sci. 2014 Feb;3(2):296-306.

5 . Benzie IF, Srain JJ. The ferric reducing ability of plasma (FRAP) as a measure of "antioxidant power": The
FRAP assay. Anal. Biochem. 1996 Jul 15;239(1):70-76. [PubMed] [CrossRef]

6. Petkova N, Petrova I, Ivanov I, Mihov R, Hadjikinova R, Ognyanov $\mathrm{M}$, et al. Nutritional and antioxidant potential of carob (Ceratonia siliqua) flour and evaluation of functional properties of its polysaccharide fraction. J Pharm Sci \& Res. 2017; 9(11): 2189-2195. [CrossRef]

7. Kermasha S, Goetghebeur M, Dumont J. Determination of phenolic compound profiles in maple products by high -perfomance liquid chromatography. J Agric Food Chem. 1995; 43(3):708-716. [CrossRef]

8. Sikorska E, Gorecki T, Khmelinskii IV, Sikorski M, De Keukeleire D. Fluorescence spectroscopy for characterization and differentiation of beers. J Inst Brewing. 2004; 110(4):267-275. [CrossRef]

9. Rice-Evans C, Miller N, Paganga G. Antioxidant properties of phenolic compounds. Trends in Plant Science. 1997 Apr 1;2(4):152-159. [CrossRef]

10. Mitev D, Vlakhov E, Vlakhov T, Peshev D, Hristova-Avakumova N, Hadjimitova V. Effect of Nanofiltration on the Antioxidant Properties of Crataegus monogyna Curative Extracts. Bulg J Phys. 2016; 43(4):311319.

11. Hadjimitova V, HristovaAvakumova N, Traykov T. Relationship between antioxidant properties and GC-MS component composition of extracts from flowers, leaves and fruits of Crataegus Oxycanta. J Advances in Agriculture. 2015;4(1):310315.

12. Luis G, Rubio C, Gutierrez AJ, Hernandez C, Gonzalez-Weller D, Revert $\mathrm{C}$, et al. Palm tree syrup: nutritional composition of a natural edulcorant. Nutr Hosp. 2012 Mar-Apr; 27(2):548-52. [PubMed] [CrossRef]

Please cite this article as: Radusheva P, Nikolova K, Petkova N, Gabrova R, Naydenova D. Optical properties and chemical characterization of woody syrup by using methods of applied photonics. J of IMAB. 2018 Oct-Dec;24(4):2250-2253. DOI: https://doi.org/10.5272/jimab.2018244.2250

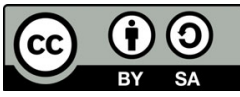

Address for correspondence:

Krastena Todorova Nikolova

Department of Physics and Biophysics, Faculty of Pharmacy, Medical University - Varna,

84, Tsar Osvoboditel Blvd., Varna, Bulgaria

E-mail: kr.nikolova@abv.bg

https://www.journal-imab-bg.org 